\title{
For the safe use of lasers in educational institutions: elementary through university
}

Fredrick Seeber

Fredrick P. Seeber, "For the safe use of lasers in educational institutions: elementary through university," Proc. SPIE 2525, 1995 International Conference on Education in Optics, (13 October 1995); doi: $10.1117 / 12.224061$

Event: SPIE's 1995 International Symposium on Optical Science, Engineering, and Instrumentation, 1995, San Diego, CA, United States 


\title{
"For the Safe Use of Lasers in Educational Institutions" \\ Elementary through University
}

Fred P. Seeber

Laser institute of Technology for Education and Research, Camden County College Blackwood, New Jersey 08012

\begin{abstract}
The use of lasers by the academic community continues to dramatically escalate. Academia is inundated with a profusion of lasers, each with a diverse function. Traditional departments such as Biology, Chemistry, and Physics have introduced the use of lasers as an essential element of tutelage. Even the more distinctive departments such as Cancer Research, Civil Engineering, Earth and Planetary Science, Plasma Fusion, Spectroscopy, and so forth, have incorporated the laser in the composition of their educational mechanism.

The literature indicates most ocular accidents happen during alignment procedures, which is an everyday activity for educational laboratories. Also, the improper use of laser safety eye wear is a major area of concern for laser safety in educational institutions.

More Class II, III, and IV lasers are used in universities, colleges, laser electro-optic technical colleges and high schools than probably any other area: for teaching, research, laboratory experiments, and demonstrations. Relatively large numbers of students work in laboratory groups in confined area, with various lasers of different wavelengths in the same laboratory. Open cavity and beam paths of Class IV lasers are common in these environments. Most educational institutions do not have laser safety officers or standard operating procedures.
\end{abstract}

This paper will discuss the development of a new laser safety standard by an ANSI ad-hoc committee and by the executive committee of the ANSI Z-136 intended to provide adequate, reasonable, and practical guidance for educators, students, and spectators found in classrooms, lecture halls, and laboratories associated with universities, colleges, high, and elementary schools.

Keywords: safe use of lasers, ANSI, academia, guidance, educational institutions, safety officer

"When the beam struck my eye I heard a distinct popping sound, caused by a laserinduced explosion at the back of my eyeball. My vision was obscured almost immediately by streams of blood floating in the vitreous humor...It was like viewing the world through a round fishbowl full of glycerol into which a quart of blood and handful of black pepper have been partially mixed..." 
Adapted from a typical laser injury victim

If this kind of accident can happen to an experienced researcher, imagine all of the potential laser dangers faced by untrained students in educational institutions. With the advent of new laser technologies and products that are finding their way into high schools, colleges, and graduate schools, the scientific community needs to investigate the safety issues associated with their use by novices.

The American National Standards Institute (ANSI) has developed excellent general safety guidelines for the safe use of lasers for industry and medicine and also communications. However, there is currently a debate in the scientific community as to whether a specific standard needs to be developed for these involved in educational settings.

A sub-committee of the American National Standard Institute Z-136 Committee has written a draft of a new laser safety standard for educational institutions. The writing of this new standard has a high priority due to the increasing number of laser accidents reported from these schools of learning. This concern is supported by statistics in recent articles on laser accidents and laser safety.

In Table I there is a proposed outline for an education laser safety standard. Some sections of the outline are quite different from other laser safety standards, for example-educational environments, and other sections align themselves with existing laser safety documents.

The literature indicates most ocular accidents happen during alignment procedures, which is an everyday activity for educational laboratories (See table II). Also, the improper use of laser safety eye wear is a major area of concern for laser safety in educational institutions.

As the laser industry expands into new areas, more research will be conducted at colleges and universities, as well as training in laser electro-optic technology two year colleges, technical schools, and laser experiments/demonstrations in high schools, middle and elementary schools. The following areas of concern must be addressed:

1. More class 4 lasers are used in universities, colleges, LEOT schools then probably any other application.

2. Many class 2, 3a, $3 \mathrm{~b}$ and some class 4 lasers are used in high, middle and elementary schools for teaching and laboratory experiments.

3. Special safety concerns are evident with the use of varied lasers of different wavelengths in the same laboratory setting. 
4. Open cavity and beam paths of class 4 lasers are common in instructional and research laboratories in colleges and universities.

5. Relatively large student numbers work in laboratory groups in confined areas.

6. Most educational institutions do not have appointed laser safety officers with proper training.

7. Standard operating procedures for class 4 and class $3 b$ laser systems in the classroom and laboratory frequently do not exist.

8. Large auditoriums are filled with students and spectators observing laser demonstrations.

The Z-136.1 Standard for the most part has not been accepted by educational institutions, because of its lack of focus to the institutions needs. Some of the special environments that need addressing are in a new standard are:

1. Classroom Environments

2. Educational Laboratories

3. University Research Environments

4. Laser Electro-optic Technology Training Schools

5. Science Fairs and Projects

In schools many of the personnel are first time laser users. The majority are teachers, undergraduate and graduate students, high school, middle and elementary students with virtually no exposure to safe laser operating procedures. On many occasions there are several different kinds of lasers situated in one laboratory; For example, it's common to find an argon ion, CW dye laser, CW mode-locked Nd:YAG/dye laser system, and excimer laser in one, single lab--to conduct experiments involving the laser spectroscopy of different samples (or even the same sample). Much of the equipment in a department is shared--that is, several students will need to operate various lasers on a "time share" basis. There are usually no guidelines on how a "system should be transferred" to another researcher or teaching laboratory. Again, no standard operating procedure. Also, many teaching and research laser laboratories have student's desks and workstations close to operating laser equipment.

The "operative word" in describing the typical teaching research laboratory is "dynamic'. There is usually a flux of students and faculty involved in a plethora of changing experiments that require new experimental set-ups involving lasers. Care must be taken to ensure that new traffic patterns, new water/electrical lines, and laser set-ups are done properly--according to prescribed safety standards. 
Unfortunately, most educational institutions do not have laser safety officers (LSO) to educate and train, develop standard operating procedures and insist that personal protection equipment be provided and used. In addition, no medical surveillance is suggested. An educational laser safety officer must be regarded in the institution as one of real authority mandated by the administrative structure. The LSO must ensure that all individuals--both students, staff and faculty--complete a comprehensive training seminar which reviews:

1. Basic laser theory and applications

2. Biological effects

3. Safety standards and precautions

4. Hazard recognition and evaluation

5. Special teaching environments

6. Procedures in case of an accident

7. S.O.P.'s for teaching laboratories and research laboratories

The LSO must inspect all teaching and research experimental set-ups involving the use of lasers--in either teaching or university research environments. This individual has the right to discontinue, cancel or postpone a demonstration or research until a safety issue is rectified. The LSO should submit a written report to Administration--on a quarterly basis--to summarize laser safety issues germane to that department or institution. He or she must get update training on the use and safety issues associated with new laser systems that are introduced during his or her tenure. The LSO is in the best position to determine when training is needed. The LSO shall approve and provide each student a copy of appropriate safetu procedures and/or rules of conduct for general laser use and shall assure that each student involved in a course of study utilizing lasers at the institution is provided with a lecture or training lesson. A laser safety test will be given to each student who should earn a grade of $100 \%$ to work with lasers. If a $100 \%$ grade is not attained, retesting will be necessary until this is accomplished. The LSO shall maintain this information on file for each working student that enters into the Nominal Hazard Zone (NHZ) of Class $3 \mathrm{~b}$ or Class 4 lasers. This file is necessary for teachers and students in laser training and research programs, for example: laser technicians and undergraduate/graduate student researchers.

The Australian Radiation Laboratory-Department of Human Services and Health has also developed a draft code of Practice on the Safe use of Lasers in Schools, the ANSI subcommittee will investigate this code to see if it can be used by ANSI as a complete document or if segments of the code can be incorporated into the draft of an ANSI standard for educational institutions.

In summary, the existing safety standards have not been accepted for the most part by educational institutions. The primary reason is these safety standards do not focus on the needs of universities, colleges, high schools and elementary schools. Namely, the Z-136.1 does not specifically address those applications of lasers which are most often found in our 
schools. In addition, the significant increase in laser accidents in schools has caused concern.

Without the availability of an educational laser safety officer responsible for training, engineering controls, personal protection devices and standard operating procedures many teachers, students and spectators are placed in a dangerous predicament. Laser accidents are waiting to happen, given the current situation, which can and must be avoided by proper guidance in the form of an ANSI laser safety standard. Time is of the essence. 


\section{$\underline{\text { REFERENCES }}$}

1. American National Standard for the Safe Use of Lasers Z-136.1, 1993 New York, $\mathbb{N Y}$.

2. American National Standard for the Safe Use of Lasers in Educational InstitutionsProposed Standard Third draft, May 14, 1995.

3. Bauman, N., Lasers Accidents: "Why Only 10\% Get Reported", Laser Medicine and Surgery News and Advances, Page 1-7, August, 1988.

4. Rockwell, R. James, "Laser Accidents: Are they all reported and what can be learned from them?" Journal of Laser Applications, October 1989.

5. Seeber, Fred P., Laser Practices and Problems Educational Institution's Proceedings International Laser Safety Conference, Cinn., Ohio, 1992.

6. Seeber, Fred P., Laser Safety in the Classroom: What Guidance is available? 13th International Congress on Applications of Lasers and Electro-Optics proceedings 1993.

7. Sliney, D.H. and Wolbarsht, M., "Safety with Lasers and Other Optical Sources", Plenum, New York, 1980. 
TABLE I

Table of Contents

$\begin{array}{ll}\text { 1. } & \text { General } \\ \text { 1.1. } & \text { Scope } \\ 1.2 & \text { Application } \\ 1.3 & \text { Laser Safety Officer (LSO) }\end{array}$

2. Definitions

3. Hazard Evaluation and Classification

3.1 General

3.2 Laser and Laser System Hazard Classification

3.3 The Environment in Which the Laser is Used

4. Control Measures

4.1 General Considerations

4.2 Control Measures by Grade Level

4.3 Multi-Use Laser Facility

4.4 Educational Laser Safety Committee

4.5 Engineering Controls

4.6 Administrative and Procedural Controls

4.7 Personnel Protective Equipment

5. Laser Safety and Training Programs

5.1 General

5.2 Student Laser Safety Training

5.3 Faculty and Staff Laser Safety Training

6. Medical Surveillance

6.1 General

6.2 Faculty and Staff Examinations

6.3 Student Examinations

6.4 Frequency of Medical Examinations

7. Non-Beam Hazards

7.1 General

7.2 Fire and Explosion Hazards

7.3 Waste Disposal

7.4 Laser Dyes

7.5 Confined Space

7.6 Laser Generated Air Contaminants 
7.7 Electrical Hazards

7.8 Optical Fibers

\section{Appendices}

Appendix A, Maximum Permissible Exposure

Appendix B, Control Measures for Laser Classes

Appendix C, Nominal Hazard Zones for Various Lasers

Appendix D, Warning Signs

Appendix E, Entryway Controls and Laser Installations

Appendix F, Guide for the Organization and Implementation of Laser Safety and Training Programs

Appendix G, Medical Surveillance 
TABLE II

\section{Causes of Laser Accidents Percentage of Occurrence}

FREQUENCY OF OCCURRENCE

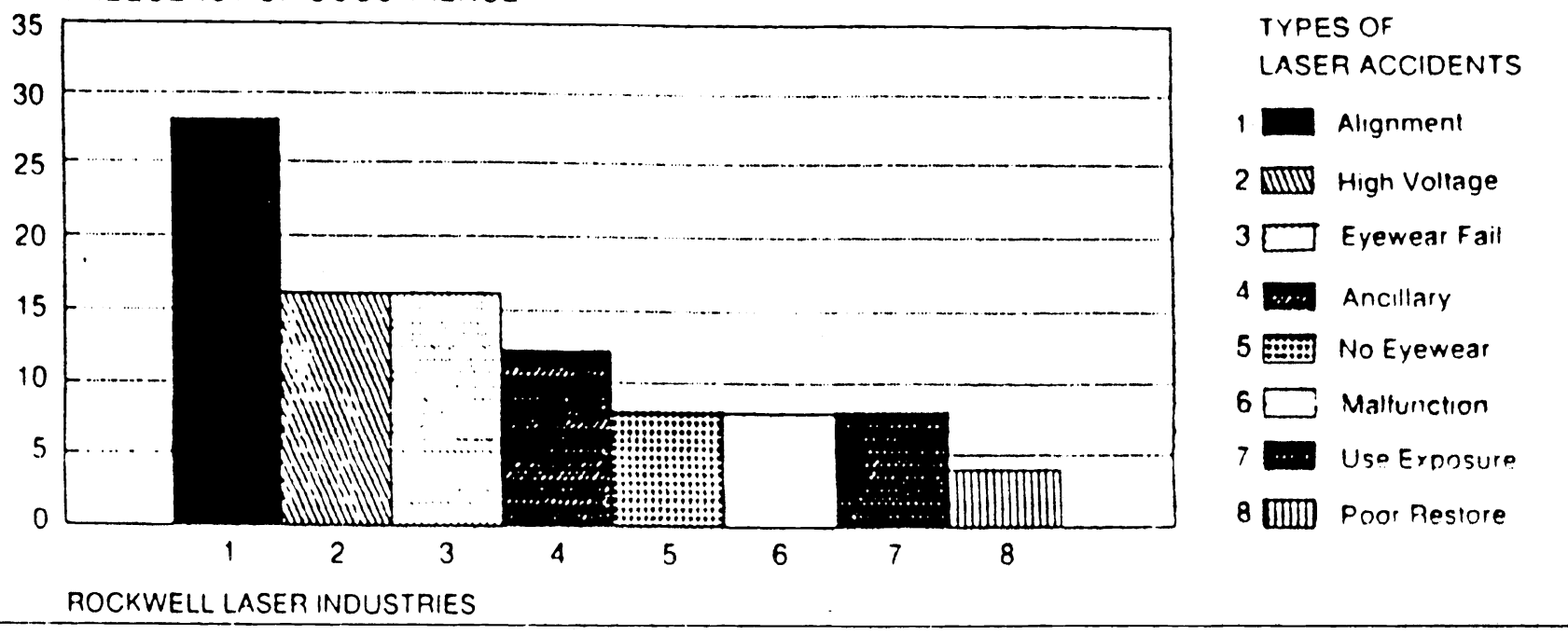

